\title{
Being there for my grandchild: grandparents' responses to their grandchildren's exposure to domestic violence
}

\author{
Linn Sandberg \\ Linköping University Post Print
}

tweet

N.B.: When citing this work, cite the original article.

Original Publication:

Linn Sandberg , Being there for my grandchild: grandparents' responses to their grandchildren's exposure to domestic violence, 2014, Child and family social work.

http://dx.doi.org/10.1111/cfs.12123

Copyright: Wiley

http://eu.wiley.com/WileyCDA/

Postprint available at: Linköping University Electronic Press

http://urn.kb.se/resolve?urn=urn:nbn:se:liu:diva-104145 


\begin{abstract}
:
Grandparents whose grandchildren are exposed to domestic violence are faced with some unique challenges in their grandparenting, which have thus far been little discussed in research. This article discusses the narratives of ten Swedish grandparents whose grandchildren have been exposed to violence towards their mother. The aim was to explore grandparents' narrations of their responses in the face of violence, and their understanding of the role they play in their grandchildren's social networks. Two significant responses are discussed: "being there" and "acknowledging the independence and self-determination of the adult children". Grandparents experienced these responses as contradictory, and felt powerless when it came to their possibilities to protect their grandchildren. The article suggests that grandparents could be a resource for domestic violence services and social work practice needs to assess the roles of grandparents of children exposed to domestic violence. Social workers should consider the challenges these grandparents are facing and what support they may need in order to support their grandchildren.
\end{abstract}

\title{
Key words:
}

Keywords: Grandparents; Children exposed to violence; Responses; Grandparenting;

Domestic Violence

There is now a significant bulk of research examining the experiences of children witnessing violence in the family (Överlien, 2010). ${ }^{1}$ Yet, largely missing within this field are studies that focus on the social networks of children, how they respond when they become aware of the violence, and the support they may provide. This article focuses on people who often play a significant role in the lives of children: grandparents. Knowledge on the roles and responses of grandparents in the event of domestic violence (DV) may be useful for social workers who aim to actively engage with and support the social networks of children.

Existing literature suggests that grandparenting plays an increasingly important role in contemporary societies (Timonen \& Arber, 2012). Greater longevity and demographic shifts towards fewer grandchildren per grandparent are likely to result in "longer and potentially stronger bonds" between grandparents and grandchildren (Ibid, p.3, Connidis 2010). However, research on DV has paid little attention to the role of grandparents and there is thus little knowledge of how grandparents experience their roles and respond when their grandchildren are experiencing DV (cf. Bullock, 2006).

This article discusses the narratives of ten Swedish grandparents of children experiencing DV, mainly that of the children's father towards their mother. The aim is to explore grandparents' narrations of their social responses and understandings of their own role in the 
grandchildren's social networks. Using a qualitative approach, the article asks questions about what grandparents experience as their possibilities and difficulties in supporting their grandchildren. Generally, very few studies have directly addressed the experiences of "third parties", the informal social networks of victims of DV, how they make sense of the violence, and why they do or do not respond (Klein, 2012, p. 75). The few studies of this kind that do exist focus primarily on the social network responses of the abused woman and not her children (Beeble et al., 2008; Beeman, 2001; Latta \& Goodman, 2011). The study on which this article is based consequently focuses on the children's networks, and in this particular article on the experiences of grandparents.

Listening to the voices of grandparents is important for several reasons. Social support has been shown to provide an immediate stress buffer for children but also have a mediating role and to be related to children's adjustment in cases of DV (Beeman, 2001; Owen et al., 2008). Grandparents may act as positive role models and a good relationship may function as a protective factor for disruptive behaviour among children experiencing DV (Beeman, 2001; Bridges \& Roe, 2007; Grizenko \& Pawliuk, 1994). Understanding how grandparents respond to DV may thus increase the knowledge of how to prompt resilience among victimized children. Overall, the responses of social networks have often been overlooked and may thus be a "potential, and largely untapped, resource for intervention" (Goodman \& Smyth, 2011; Klein 2012, p. 2). Knowing more about the experiences of grandparents could thus be useful for social services or other formal support agencies to make further use of the children's networks. But grandparents may also be in need of further formal support, particularly in cases in which they engage in extensive co-parenting (Bullock, 2006).

It is moreover important to identify cases where grandparents fail to be consistent sources of support. Research points to a particularly contradictory role of parents of DV victims and DV may cause conflict among the extended family, which influences also on the grandparentgrandchild relationship (Belknap et al., 2009; Bosch \& Bergen, 2006; Rose et al., 2000). A study by Bosch \& Bergen (2006), for example, indicates that family members and kin who would otherwise be supportive may be less responsive in the event of DV. Contextual reasons, such as the grandparents being threatened by the abuser, may also impact on their possibilities to respond (Klein, 2012). 
Knowing more about the role and responses of grandparents may moreover contribute to forging theoretical discussion on grandparental agency in a wider sense (cf. Timonen \& Doyle, 2012). Supportive grandparents matter as part of children's social networks when they experience DV; thus understanding their agency is of importance in research and social work practice. Social workers may have been involved mostly with custodial grandparents, and may therefore miss out on the involvement of grandparents in other instances. ${ }^{2}$

In this article the term "domestic violence" (DV) is used and equals the term "intimate partner violence", terms which refer to violence towards individuals who are or have been in an intimate relationship (Basile \& Black, 2011). Although DV sometimes also denotes violence by parents towards children or between other members of the family, this article focuses on violence between adults whereby the children have been exposed through either seeing, hearing, being directly involved (for example trying to intervene), or experiencing its aftermath (Holden, Geffner \& Jouriles, 1998). Men's violence towards women has been a prioritised area within Swedish politics on gender equality for some decades (Wendt Höjer 2002), and more recently practitioners and researchers have also highlighted children's experiences of DV. Today children experiencing violence in the home are considered victims according to the Swedish social service act. Swedish research on children experiencing violence is currently relatively abundant and has increasingly involved also the voices of children themselves (Eriksson \& Näsman 2010; Grip 2012; Källström Cater 2004; Överlien \& Hydén 2009). Presently there is no existing research on the social networks of children experiencing DV, however, and thus no knowledge exists in Sweden on responses of grandparents or other significant people in children's lives, besides parents.

\section{Details of the study and participants}

The empirical material discussed in this article consists of nine interviews with ten individuals who were all grandparents or great-grandparents of children who had experienced DV. ${ }^{3}$ One interview was done jointly with two great-grandparents, who were a married couple. The interviews lasted 60-80 minutes and used a semi-structured narrative and teller-focused approach (Hydén, f.c.). Depending on the ambiance and the established rapport between the interviewee and me, I chose to open either with a question about their relationship with their grandchildren or with a more direct question: "tell me what's happened in your family?" The material has been analysed using a combination of thematic and narrative analyses (Braun \& Clarke, 2006; Riessman, 2008). 
All interviewees were white with Swedish background. Six of the interviewees were born between 1951 and 1960, while four were born in the 30s and 40s. Moreover, half of the interviewees worked. They had between one and three grandchildren, both boys and girls, who had experienced DV. The grandchildren's ages ranged between newly born and adolescence (17 to 18 years old). The grandparents of this study all narrate having a more or less close and good relationship with their grandchildren. The closeness to the grandchildren can be linked to how all lived geographically close to their grandchildren; all were less than an hour away and several saw their grandchildren every week. The homes of the grandparents were often refuges for the children when violence occurred. Several of the interviewees had been involved in the local treatment and support programme, and were thus as a self-selected sample perhaps more engaged with the abused woman and the grandchildren than many other grandparents are.

Of the ten interviewees, all but one were maternal grandparents. Also, notably, all but one of the interviewees were women. This reflects a general trend in research on grandparenting. As pointed out by Timonen \& Doyle (2012, p. 160), "gender and lineage (maternal versus paternal) are highlighted in the literature as key variables that influence contact and support provision between (grand)parents and (grand)children following breakdown in the middle generation". The maternal grandmother bias of this study is important to note as experiences may differ greatly between paternal and maternal grandparents and men and women. When the grandmother is also the mother of the perpetrator this may involve extensive negotiation and challenges when making sense of the violence and the grandchildren's needs, as was visible with the one paternal grandmother participating in this study.

The grandparents in this study were recruited either through contacts with the social services in the region of the study or through a local treatment and support programme for abusive and abused people and their children. One of the interviewees was contacted through snowball sampling in another study. In all cases but two the violence their grandchildren had experienced was towards their mother by their father. In all cases, the DV narrated by the grandparents included physical violence: kicking, pushing, strangling, hitting or wrestling to the ground. But the interviewees also narrated extensive psychological and emotional violence, ranging from threats of violence and breaking into the house to killing animals and destroying property. No sexual violence was discussed. Most grandparents were not sure what 
kind of or how much violence their grandchildren had experienced. This was often related to the age of the grandchildren; some were very young when living with the DV and therefore spoke very little or not at all. It was thus not considered viable to ask them about their experiences. At the time of the interview the abused mothers of the children had been separated or divorced from the abuser for periods between nine months to 15 years prior to the interview.

Naturally, meanings and normative scripts of grandparenting are contextually and culturally variable and the Swedish context of this study should also be noted. The role of grandparents has gained increasing attention in research in recent years, and this research also points to contextual variations in grandparenting (Timonen \& Arber 2012). Research on meanings of and practices of grandparenting in Sweden is presently lacking, however. Nevertheless, it seems evident that situation of white Swedish families, the group to which the interviewees in this study belonged, differs from, for example, Bullock's (2006) study on African-American grandparents raising children exposed to DV. As Bullock argues, caring for the extended family is a strong cultural value in the African-American community and particularly grandmothers are understood as central figures in the kin. While grandparents are understood as important in the lives of children in white Swedish families, they clearly hold a less central position than the grandparents of Bullock's study. The Swedish norms regarding grandparenting are expressed, for example, in the book Grandparents' book on Grandchildren (Alfvén \& Hofsten, 2007, Original Swedish title: Barnbarnsboken för moroch farföräldrar), a popular book written by two psychologists. It lists the "rights" and "wrongs" of grandparenting and states, for example, that grandparents should not visit uninvited and unexpected, should not criticize or intervene in the upbringing of the grandchildren, and should not criticize (adult) children, in-laws or grandchildren (Alfvén \& Hofsten 2007, p. 98). This reflects what May et al. (2012) discuss as two pervasive grandparenting norms in western Europe: "being there" and "not interfering", norms which, as I will show, had great impact also on grandparents responses in this study. The positioning of grandparents in a Swedish context is also reflected in the legal status, which is presently unclear. Close relatives such as grandparents may apply to the Social Welfare Board for the right to see their grandchild, but are not legally entitled to have access to the child (Olsson, 2011).

\section{FINDINGS}




\section{The importance of "being there" - a negotiated response}

Analysing the wide variety of responses to the violence that the interviewed grandparents narrate, it seems evident that these grandparents are central actors when the grandchildren experience DV and are important sources of support. Their responses include giving practical, financial, material and emotional support, for example talking to and comforting the grandchildren, as well as encouraging and persuading the grandchildren's mother to leave the abusive relationship. Moreover, several of the grandparents interviewed for this study seemed to play a central role as "a spider in the web", maintaining contact with others in the children's social networks. They also narrate active attempts to stop the violence, mostly by persuading the victimized woman to leave. Some of the grandparents had been in contact and actively engaged with the police and social services, although this was often experienced as complicated because they did not know the extent to which they should report the violence and the children's situation, as they did not want to aggravate the situation. The greatgrandparents in the study were less involved and seemed to depend more on the information they received from their children, the grandparents, and thus held a less central position in the social network.

There is one thing in particular which resounds in the grandparents' responses to questions about their role and possibilities of supporting: the importance of "being there". This was mentioned by all interviewees as important, and in all cases but one the specific expression "being there" was used. There was not one unequivocal meaning of "being there" among the different grandparents, however. It seemingly involves providing both emotional and material/practical support, as expressed by Eva-Marie:

Well I don't have the financial possibility to support them with money. The only thing I can do is be there when they need it, really. Well, when things are most serious, making sure there's food on the table sort of. [...] I don't want to overstate myself, but I'm there when needed. And Grandpa is too.

Being there often seemed to involve listening and being someone to talk to, for both the grandchildren and the victimized woman. Harriet, for example, talks about how one cannot simply stay under the same roof, but has to "be there as a human being" and listen in a more profound way. 
The emphasis on being there as expressed by the interviewees should not be understood as exclusive to grandparents whose grandchildren experience DV. May and colleagues (2012, p.139ff) discuss "being there" as a very strong "grandparenting norm" overall. They argue that it "evokes the image of a grandparent waiting in the wings at the ready to be called upon", and argue that it as such is a very "other-orientated" and passive concept (May et al. 2012 , p.145). The narratives of the grandparents in my study do indeed point to a very otherorientated approach, which is not surprising given the circumstances their grandchildren are in. To the interviewees, being there seems to involve unconditional and relentless support and presence in their grandchildren's lives. While May et al. (2012) discuss how grandparents often negotiate and sometimes resist being on constant call, the grandparents in this study did not express this. On the contrary, several interviewees express how they are or have been ready to step in and help their grandchildren (and children) at any point. To mention only a few examples: Gudrun mentions keeping her phone with her at all times; Harriet describes how her daughter calls and urges her to come over to stop the abusive husband from fighting and becoming violent; Elisabeth mediates between her abusive son and his partner, and persistently tries to take her grandson away from the violence; Christina tells of being called up and going out to rescue her daughter and grandchildren in the middle of the night, and of helping them move out several times.

Although the "being there" of the grandparents of my study is indeed a very other-orientated position and response there is a need to complicate the assertion by May et al. (2012) that being there is necessarily a passive response. Instead it is a very negotiated response, which greatly depends on how one perceives one's possibilities to interfere and stop the violence. Although all interviewees underlined the importance of being there, they differ significantly in what they understand and count as being there in a situation whereby one's grandchildren are experiencing DV. For some, being there was passive in the sense that they did not feel they had the right or possibility to interfere. Harriet, for example, whose daughter had been abused by her alcoholic husband, and whose grandsons had therefore experienced DV throughout their childhood, had visited regularly and acted as protection against the violence:

Harriet: Well sometimes he got angry and then she [the daughter] called me, whispering "Could you come over now?" [...] And then I came over, but [she said] "Don't say anything”. And well nah, then I didn't, 'cause I didn't want to 
cause more fighting. But I had to stay for several hours, because it didn't go away immediately.

Harriet's way of being there was thus connected to physically being there. Although she was well aware of the violence, she did not attempt to challenge the perpetrator or actively make her daughter leave the abusive relationship. Instead, her strategy was to act as a physical buffer against the violence, because the grandchildren's father respected her, she says, and was not physically violent towards her daughter when Harriet was around. Harriet makes sense of this response by pointing to the problems in her own relationship, in which she was in many ways subordinated to her husband. She also speaks of how her husband (the children's grandfather and the abused woman's father) was friends with the perpetrator and sternly opposed divorce, and this apparently impacted on her responses and how she could intervene.

For others, however, being there is more linked to active interventions to make the violence stop and make the woman leave the relationship. Eva-Marie argues that one has to think of the children foremost and thus that the abused mother needs to exit the relationship even if this is hard. Annelie is highly critical of her grandchildren's paternal grandmother, who she says supports her abusive son rather than the grandchildren. Similarly to Harriet, discussed above, the paternal grandmother visits and stays at their home often, and when she is there everything is more civil and non-violent. But Annelie argues that she should stand up more for her grandchildren:

Annelie: And then there's the thing, that she's been subject to this herself [being abused by her partner]. So she's probably scared. But I feel that when it comes to the grandchildren one has to take the fight and show a little opposition.

So while some make sense of "being there" as physically being there and temporarily hindering the violence, others understand it as being supportive of the grandchildren and thus being more active and keeping them from experiencing violence. Being there may consequently be a highly negotiated response, which is open to many different meanings. Pointing to how one is there for one's grandchild is a way of narrating a morally responsible self, of accounting for a caring and considerate response to the violence, although one's possibilities to respond may be (or be experienced as) different. Emerging as someone who 
"is there" for the children may thus be important to emerge as a positive and caring grandparent, particularly in the event of violence (cf. Finch \& Mason, 1993, p. 33). This does not mean that some grandparents in this study did not genuinely care for their grandchildren; my argument is rather that although the possibilities to respond may be different, narrating one's self as someone who "is there" is a sufficiently open category to show that one is a caring grandparent, although one's possibilities for action may vary.

\section{Acknowledging the independence and self-determination of the adult children}

Being there is also a negotiated response in the sense that grandparents may balance between a wish to intervene to protect the grandchildren while at the same time not wanting to act against the wishes of the children's mother. Christina is worried about and critical of her daughter's choice to return to her abusive partner. But she speaks of the difficulties involved with criticizing her, as this may jeopardize her relationship with her grandchildren and risk her being cut off from them (cf. May et al. 2012, p. 149):

Interviewer: So what she did was, she stopped talking to you?

Christina: Yes, that's when we questioned how she could return to him after what had happened [the abuse leading to a police report]. Well it wasn't for long, 'cause you sort of had to...(laughs). You wanted to see the grandchildren too.

Christina expresses that she had to reconsider her criticism of her daughter's actions and the continuation of the relationship with the abusive partner, since her questioning would make the daughter stop talking to her and subsequently result in a loss of contact with her grandchildren. In the literature on grandparenting the grandparent-grandchild relationship is often described as "mediated", dependent on the middle generation as a "relational bridge" (Timonen \& Arber, 2012, p.9). After a divorce this is particularly complicated as a former son- or daughter-in-law may deter grandparents' access to their grandchildren. This may be particularly accentuated in cases of DV, whereby a mother may feel that granting the paternal grandparents access to the children may result in contact with the perpetrator, "who could inflict (further) harm" (Doyle et al. 2010, p.591). Paternal grandparents in particular are more likely to lose contact with grandchildren after a divorce, and this risk may increase in cases of high conflict, like DV (Doyle et al., 2010; Timonen \& Doyle, 2012). However, Christina’s 
narrative suggests that in cases of DV, maternal grandparents may also have to balance their responses in ways which do not jeopardize their relationship with their grandchildren.

Christina tells of how she was greatly concerned for the grandchildren's wellbeing, but was unable to do anything. She "had to accept it" and making the decision to leave was up to her daughter since she was an adult.

Experiencing the relationship with the grandchildren as mediated and that this impacted on one's responses is something several other interviewees express. Annelie talks about how she has to follow her daughter's wishes, and links this to how it is "her family that it's about":

Annelie: Well, for my daughter all I can do is be there, 'cause sometimes I want to do things and she just feels like it would make things worse, and then I have to stand back, 'cause I stand by her no matter what she decides. I'm behind her. Cause it's about her and then I cannot bypass her, even if I want to sometimes. [.... Well it's important that she gets to decide 'cause it's her family that it's about $[\ldots]$ We discuss things back and forth, but I'm following her line whatever she decides on.

The way Annelie underlines how her daughter is the decision-maker reveals how the independence and self-determination of one's child seem to be an important issue. Another interviewee, Elisabeth, has been very involved in the care and upbringing of her grandchild since her son was incarcerated for a year as a result of his violence towards his partner. During this year she is supporting her grandson's mother a great deal, partly because she feels she has to compensate and take responsibility for her son's actions. But Elisabeth also reflects on the fact that her son and his partner are adults and on how this impacts on her involvement. At the birth of her grandson, Elisabeth had chosen to be less involved in her son's violent relationship, she had made had "made her opinion clear" she says and other than that she felt that the decision was theirs not her.

Elisabeth: Really, I think I distanced myself a bit more. Even though it may seem strange. They were adult enough to decide to give birth and have a child together. 
Christina, Annelie and Elisabeth, all in different ways, point to their children's adulthood and how this links to autonomy and being able to make their own decisions. These narratives could be understood as expressions of what May et al. (2012,139f) discuss as another strong "grandparenting norm", besides "being there"; that of "not interfering". May et al. argue that the norm of non-interference was related to an ideal by which parents should let their adult children be independent, and that grandparents should not interfere in the upbringing of the grandchildren. The study by May and colleagues also suggests that there were circumstances in times of crisis when grandparents understood it to be legitimate and right to interfere. Clearly, DV was a circumstance of crisis, and the narrated responses show that the grandparents were more involved in the care and upbringing of the children than they might have been under other circumstances. Still, the narratives in this study suggest that the grandparents were very much torn between the wish to protect their children and grandchildren on the one hand and arguing that their children were adults and consequently had to make their own decisions regarding their own families on the other.

Following May et al. (2012, p. 144), grandparents are caught in a difficult situation in relation to the non-interference norm as they try to grandparent and parent at the same time. In this case, they seek not only to give independence to their child and make them decide on their own lives, but also to protect their grandchildren (and their children) from violence. Finch \& Mason (1993) argue that the negotiation of responsibilities in families is important in order to achieve the right balance between independence and dependence. A family member being too dependent on other kin was seen as negative, as dependency is also linked to subordination, they argue.

The interviewees' emphasis that they cannot interfere because it is not a matter of their family but rather their adult children's family also reflects that the grandparents do not automatically position themselves as part of their children's new family. Despite their involvement with the grandchildren, which often extends to co-parenting when the grandchildren's father is absent or not fulfilling his parental responsibilities, they often do not feel they have a say in their grandchildren's situation. This must partly be understood in relation to the position of grandparents in the Swedish context, where they are not automatically understood as kinkeepers but are positioned as more peripheral in the family network. Swedish research has pointed to the fairly strong norm of the nuclear family within Swedish courts and social services where fathers should still have access to their children even in cases of DV (Eriksson 
2002; 2003, Eriksson \& Hester, 2001). My study indicates that grandparents also take up and make sense of families, primarily in terms of nuclear families where parents are the primary decision-makers in the children's lives even in cases where children are exposed to DV by one of the parents.

Notably, however, the way the grandparents respond by wanting to listen to the wishes of their adult children, to grant them self-determination, is not exclusive to grandparents. Friends and other relatives may also find it important to listen to what victims of DV want, even though this may go against what they feel is best for the victim (Latta \& Goodman, 2011). However, I argue that the intergenerational aspect - that grandparents are both parents and grandparents - may further complicate the situation. It is noteworthy that discussions of autonomy and the right to choose are primarily linked to the adult children and not as much to the grandchildren. The grandchildren are consequently largely positioned by the grandparents as dependent and non-autonomous, regardless of their age - whether they were teenagers or young children (cf. Hockey \& James, 1993).

All in all the balancing between "being there" to support and protect the grandchildren while not intervening in order to grant their adult children self-determination and independence result in evident feelings of powerlessness. The interviewees repeatedly voice that there was "not much I could do". Being close to someone who is being abused in an intimate relationship may be experienced as a very powerless and frustrating situation in which an individual has to, in the words of Latta \& Goodman (2011, p.984ff), "struggle to define his or her role" in engaging with the victim of the abuse (also: Goodkind et al., 2003). For the grandparents in this study, the experiences of powerlessness are particularly manifest as their relationship with their grandchildren is "mediated", dependent on the middle generation (Timonen \& Arber 2012, p.9 referencing Gladstone, 1989). When Christina, discussed earlier, tells how she could not go on questioning the continuance of the relationship between her daughter and her abusive partner because this might keep her from seeing her grandchildren, this clearly reflects the powerlessness she experiences in her mediated relationship with her grandchildren. This is eloquently narrated by Elisabeth, who describes her feelings of powerlessness in terms of "sitting in an arena watching this game I can't influence":

Elisabeth: The most difficult part has been that I can't stop [the violence] really - it's the powerlessness. I really can't do anything. More than compensating. 
That's the only thing; other than that I can't do anything. Markus [her son] is an adult. I can't direct him; if I could it would all have been fine. [...] It's like I'm sitting in an arena watching this game I can't influence, I'm afraid. I may try to compensate. But I can't influence the outcome or what happens. [...] But then you see this child running around down there in the game. And then you have to try and take him out of that game.

Dependency on the middle generation may be experienced as particularly complicated in cases of DV. Grandparents are often intimately interwoven into their grandchildren's lives when they are exposed to DV, yet they are not fully in a position to intervene as the narratives of this study reveal.

\section{Concluding discussion - considerations for research and practice}

Very little is known about the experiences of grandparents whose grandchildren are exposed to DV, and this article has been an attempt to contribute to a research field that is this far largely absent. The many responses that the grandparents in this study narrate indicate that grandparents may play a very active and involved role in the lives of grandchildren who are exposed to DV. The grandparents narrate a range of responses, from financial and instrumental support to emotional support.

I have discussed "being there" as a significant response, something all interviewees understood as their most important role. But being there meant different things to different interviewees. For some it could involve being physically there, temporarily preventing the violence from happening but not actively seeking to make it stop. For others, however, this was understood as a non-sufficient response, and being there instead entailed active interventions to make the violence stop, get the abused woman to leave and let the children live a life altogether free from violence. Overall I have discussed being there as a negotiated position, a way of responding in different ways depending on one's own biography and how one experiences one's possibilities for action.

The response of "being there" should also be understood in the light of how grandparents balanced between the sometimes conflicting wishes and needs of the their adult children and their grandchildren. On the one hand the interviewees acknowledged their children's right to self-determination, that they were adults and should thus decide on their own lives. On the 
other hand, they were concerned and wished to protect their grandchildren from being further exposed to violence. This was sometimes experienced as very complicated, particularly when the children's mother continued to live with the abuser. Being there was thus closely tied to the grandparenting norm of non-intervention, and was an overall possible response in a situation in which all interviewees seemed to experience a great deal of powerlessness, not least from the mediated character of their relationship with their grandchildren.

The aim of this article has been to make some empirical contributions to studies on grandparenting and the grandparent-grandchild relationship in relation to DV. Still, the sample of this study is limited - not only in terms of number of participants - and calls for more qualitative and quantitative studies on grandparents' responses and ways of making sense of DV and of children as witnesses. One of the limitations of this study is that it deals foremost with the responses of maternal grandmothers. The one interview with a paternal grandmother in this study suggests that paternal grandparents may face even more complex situations when both handling and making sense of the violence of their son and the need to protect their grandchildren. The paternal line thus needs further study. Also grandparenting must be conceptualized as a gendered phenomenon. Being there is a clearly gendered response that connotes care and emotional support in specific ways. The interviewees speak a great deal about the responsibilities of women towards grandchildren, both their own and those of other grandmothers. It is remarkable, however, how the role, responses and responsibilities of grandfathers are discussed very little. Future research should thus explore the (non-)responses of grandfathers (Beeble et al., 2008; Taylor \& Sorensen, 2007). Not least, it may be interesting to look into male collusion - how grandfathers may more readily support or excuse the perpetrator, as is suggested by one interview in this study (Klein, 2012).

The narratives in this study are also limited in the sense that they tell little of how the children themselves experience their grandparents' responses. What is a child's perception and understanding of a grandparent being there when he or she is exposed to DV? Future research should involve both children and grandparents to study how the intergenerational relationship is negotiated and affected in cases of DV.

The grandparents in this study were constantly involved in a balancing act whereby they on the one hand sought to "be there" enough to protect and engage in the wellbeing of their grandchildren, while on the other hand not aggravating the situation and causing further harm. 
These particularly problematic situation needs to be considered by social workers and inform social work practice with families and children. First of all social workers must assess the roles of grandparents of victimized children, to identify their involvement with the children and their understanding of the violence. Not all grandparents can be assumed to be positive and supportive of their grandchildren and it is thus necessary to also identify potential harmful responses (Goodkind et al. 2003; Trotter \& Allen 2009). Importantly, the needs of the children rather than those of grandparents and other adults need to be prioritized. It is important also to identify how DV may change the relationship between grandparents and grandchildren and to address the difficulties grandparents may face when trying to grandparent in this situation. This involves inventorying the need for support that grandparents may require. Although not all grandparents wish to be involved with the formal child welfare system, the narratives of this study, on feelings of great powerlessness suggest that for some grandparents the backing of social workers to support grandchildren was wanted. In these cases, how can social workers help grandparents to "be there" and intervene to improve the situation for their grandchildren? This study included grandmothers who themselves had been victims of abuse and it is thus necessary to understand the particular kinds of support these women may need. The gendered aspect of grandparenting should also be considered, and a social workers must ask questions on how expectations on grandparents may vary in relation to gender and how grandfathers may become increasingly involved to support and care for grandchildren who experienced DV.

This article aims to stress the importance of understanding DV as part of a community context and to identify the resources at hand within children's social networks (Goodman \& Smyth 2011, p.80). Involved and caring grandparents who are there for their grandchildren could serve as resources for DV services and social workers may consequently help in the negotiation of family roles and responsibilities within the extended family when children are exposed to DV.

\section{References}

Alfvén, M. \& Hofsten, K. (2007). Barnbarnsboken: för mor- och farföräldrar. Stockholm: Prisma

Basile K. C. \& Black M. (2011). Intimate partner violence against women, In: Renzetti et al. (eds.) Sourcebook on violence against women. 2. ed. Los Angeles: Sage. pp. 111-131.

Beeble, M., Post, L., Bybee, D., Sullivan, C. (2008). Factors Related to Willingness to Help 
Survivors of Intimate Partner Violence. Journal of Interpersonal Violence, 23, 1713-1729.

Beeman, S.K. (2001). Critical issues in research on social networks and social supports of children exposed to domestic violence. In: Graham-Bermann, S. \& Edleson, J., Domestic violence in the lives of children: The Future of Research, Intervention and Social Policy, 1st ed Washington, DC: American Psychological Association, 219-234.

Belknap, J., Melton, H., Denney, J. Fleury-Steiner R. \& Sullivan, C. (2009) The levels and roles of social and institutional support reported by survivors of intimate partner abuse.

Feminist Criminology, 4, 377- 402.

Bridges, L. \& Roe, A. (2007). Children's Perspectives on Their Relationships With Grandparents Following Parental Separation: A Longitudinal Study, Social Development, 16, 539- 554.

Bullock, K. (2006). Get Thee Behind Me: African-American Grandparents Raising Grandchildren Who Experienced Domestic Violence. In: Hampton R. \& Gullotta T. (eds.) Interpersonal Violence in the African-American Community: Evidence-based prevention and treatment practices, New York : Springer 149-163.

Bosch, K. \& Bergen, B. (2006). The Influence of Supportive and Nonsupportive Persons in Helping Rural Women in Abusive Partner Relationships Become Free from Abuse. Journal of Family Violence, 21, 311-320.

Braun, V. \& Clarke, V. (2006). Using thematic analysis in psychology. Qualitative research in Psychology, 3, 77-101.

Connidis, I. (2010). Family ties and aging, (2 ${ }^{\text {nd }}$ edn), Los Angeles CA: Pine Forge Press (cited in Timonen \& Arber 2012)

Doyle, M., O’Dywer, C \& Timonen, V. (2010). "How Can You Just Cut Off a Whole Side of the Family and Say Move On?', The Reshaping of Paternal Grandparent-Grandchild Relationships Following Divorce or Separation in the Middle Generation. Family Relations, $59,587-598$

Eriksson, M. \& Hester, M. (2001) Violent Men as Good-enough Fathers? A Look at England and Sweden. Violence Against Women, 7, 779-798.

Eriksson, M. (2002). Men's violence, men's parenting and gender politics in Sweden. NoraNordic Journal of Women's Studies, 10, 6-15.

Eriksson, M. (2003). I skuggan av Pappa: familjerätten och hanteringen av fäders våld. Diss. Uppsala : Univ., 2004

Eriksson, M. \& Näsman, E. (2010) Interviews with children exposed to violence. Children \& Society 26, 63-73.

Finch, J. \& Mason, J. (1993). Negotiating family responsibilities. London: Routledge. 
Gladstone, J.W. (1989). Grandmother-grandchild contact: the mediating influence of the middle generation following marriage breakdown and remarriage, Canadian Journal on Aging, 8, 355-365. (cited in Timonen \& Arber 2012).

Goodkind, J., Gillum, T., Bybee, D., Sullivan C. (2003). The Impact of Family and Friends' Reactions on the Well-Being of Women With Abusive Partners. Violence against Women, 9, 347-373.

Goodman, L. \& Smyth, K. (2011). A Call for a Social Network-Oriented Approach to Services

for Survivors of Intimate Partner Violence. Psychology of Violence, 1, 79-92.

Grip, K. (2012). The Damage Done, Children Exposed to Intimate Partner Violence and their Mothers - Towards empirically based interventions in order to reduce negative health effects in children. Dissertation Gothenburg: Gothenburg University.

Grizenko, N. \& Pawliuk, N. (1994) Risk and Protective Factors for Disruptive Behavior Disorders in Children. American Journal of Orthopsychiatry, 64, 534-544.

Hockey, J. \& James, A. (1993) Growing up and growing old: ageing and dependency in the life course. London: Sage.

Holden, G.A., Geffner, R. and Jouriles, E.N. (1998). Children Exposed to Marital Violence. Theory, Research and Applied Issues. Washington, DC: American Psychological Association.

Hydén,M. ( 2014 f.c) The Teller-Focused Interview: Interviewing as a Relational Practice. Qualitative Social Work.

Källström Cater, Åsa (2004). Negotiating normality and deviation: father's violence against mother from children's perspectives. Dissertation: Örebro: Örebro university.

Klein, R. (2012) Responding to Intimate Violence Against Women: The Role of Informal Networks. New York: Cambridge University Press.

Latta, R. \& Goodman, L. (2011). Intervening in Partner Violence Against Women : A Grounded Theory Exploration of Informal Network Members' Experiences. The Counseling Psychologist, 39, 973-1023.

May, V., Mason J. \& Clarke, L. (2012) Being there, yet not interfering: the paradoxes of grandparenting. In: Arber, S. \& Timonen, V. (ed.): Contemporary grandparenting: changing family relationships in global contexts. Bristol: Policy, 139-158.

Olsson, R. (2011). Rätten till mitt barnbarn-Om umgänge mellan barn och deras mor- och farföräldrar. unpublished thesis law exam, Faculty of Law, Lund University.

Owen, A., Thompson, M.,Mitchell, M.,Kennebrew, S. Paranjape, A., Reddick, T., Hargrove, G. \& Kaslow, N. (2008). Perceived Social Support as a Mediator of the Link Between Intimate Partner Conflict and Child Adjustment. Journal of Family Violence, 23, 221-230.

Överlien, C. (2010). Children Exposed to Domestic Violence : Conclusions from the Literature and Challenges Ahead. Journal of Social Work, 10, 80-97. 
Överlien, C. \& Hydén, M. (2009). Children's actions when experiencing domestic violence. Childhood 16(4): 479-496.

Riessman. C. K. (2008). Narrative methods for the human sciences. London: Sage.

Rose, L., Campbell J. \& Kub, J. (2000). The Role of Social Support and Family relationships in Women's responses to battering. Health Care for Women International, 21, 27-39.

Taylor, C. \& Sorenson, S. (2007) Intervention on behalf of children exposed to intimate partner violence: Assessment of support in a diverse community-based sample. Child Abuse \& Neglect, 31, 1155-1168.

Timonen V. \& Arber, S. (2012). A new look at grandparenting. In: Arber, S. \& Timonen, V. (ed.): Contemporary grandparenting: changing family relationships in global contexts. Bristol: Policy, 1-11.

Timonen, V. \& Doyle, M. (2012). Grandparental agency after adult children's divorce. In: Arber, S. \& Timonen, V. (eds.): Contemporary grandparenting: changing family relationships in global contexts. Bristol: Policy, 159- 180.

Trotter, J. L. \& Allen, N.E. (2009) The Good, The Bad, and The Ugly: Domestic Violence Survivors' Experiences with Their Informal Social Networks. American Journal of Community Psychology, 43, 221-231.

Wendt Höjer, M. (2002). Rädslans politik. Våld och sexualitet i den svenska demokratin. Malmö: Liber.

\footnotetext{
${ }^{1}$ In this article I alternate between the terms "children witnessing", “...exposed to" and "...experiencing”. All these terms are used within the literature (cf. Överlien 2010). As argued by Överlien (2010), the term "children witnessing violence" may exclude children's experiences of hearing, direct involvement in and experiencing the aftermath, for example seeing blood, injuries or damaged things in the home. The term "exposed to" may as such be more open, but may also position the child as a passive recipient. When using the term "children who experience violence" I do not refer to their own direct experiences of abuse and violence, but rather wish to acknowledge how living in a home with violence involves experiencing the violence.

${ }^{2}$ Research on custodial grandparents, whereby grandparents perform the upbringing of the grandchildren due to incarceration, substance abuse or other circumstances in the middle generation, is relatively extensive (cf. Timonen \& Arber 2012). However, as the grandparents in my study were not the main carers and did not have custody of their grandchildren, as well as for reasons of space, I have not reviewed this literature here.

${ }^{3}$ The interviews were conducted as part of a larger project entitled "Children and young people living in rural areas witnessing violence at home: A study of the social network's responses" in which both children and their mothers, as well as people in their social network, were interviewed. This material has not yet been analysed in the project and for this reason no comparisons can be made between the narratives of grandparents and grandchildren. The project was funded by the Swedish Tercentenary Foundation (Riksbankens Jubileumsfond).
} 